\title{
Hypogonadotropic Hypogonadism with Anosmia
}

National Cancer Institute

\section{Source}

National Cancer Institute. Hypogonadotropic Hypogonadism with Anosmia. NCI

Thesaurus. Code C75479.

An X-linked or autosomal dominant genetic syndrome characterized by

hypogonadotropic hypogonadism and anosmia. 